\title{
Orbital-Dependent Photodynamics of Strongly Correlated Clusters
}

\author{
Jacob M. Garcia ${ }^{1,2}$ and Scott G. Sayres ${ }^{1,2, *}$ \\ ${ }^{1}$ School of Molecular Sciences, Arizona State University, Tempe, AZ 85287 \\ ${ }^{2}$ Biodesign Center for Applied Structural Discovery, Arizona State University, Tempe, AZ 85287
}

KEYWORDS: Ultrafast dynamics, nickel oxide, clusters, charge recombination, orbital dependence

Understanding the role of defect sites on the mechanism and lifetime of photoexcited state relaxation is critical for the rational design of advanced materials. Here, the ultrafast electronic relaxation dynamics of neutral nickel oxide clusters were investigated with femtosecond pump-probe spectroscopy and supported with theoretical calculations to reveal that their excited state lifetimes are strongly dependent on the nature of the electronic transition. Absorption of a UV photon produces short lived (lifetime $110 \mathrm{fs}$ ) dynamics in stoichiometric $(\mathrm{NiO})_{n}$ clusters $(\mathrm{n}<6)$ that are attributed to a ligand to metal charge transfer $(\mathrm{LMCT})$ and produces metallic-like electron-electron scattering. Oxygen vacancies introduce excitations with Ni-3d $\rightarrow \mathrm{Ni}-4 \mathrm{~s}$ and $3 \mathrm{~d} \rightarrow 4 \mathrm{p}$ character, which increases the lifetimes of the sub-picosecond response by up to $80 \%$ and enables the formation of long-lived (lifetimes $>2.5 \mathrm{ps)}$ states. The atomic precision and tunability of gas phase clusters are employed to highlight a unique reliance on the Ni orbital contributions to the photoexcited lifetimes, providing new insights to the analogous band edge excitation dynamics of strongly correlated bulk-scale $\mathrm{NiO}$ materials.

In strongly correlated materials, such as transition metal oxides, the electronic structure reflects the coupling between the orbital, spin, and charge degrees of freedom. This leads to numerous competing metastable phases that are accessible via ultrafast photoexcitation and are important in opto-electronics and light harvesting. The local rearrangement of the $3 \mathrm{~d}$ electrons plays a crucial role in many properties of correlated transition metal oxide materials and supplies information on magnetic interactions. $\mathrm{NiO}$ is the prototypical strongly correlated material, whose electronic structure has been a topic of interest for decades owing to its potential to serve in numerous energy applications as an efficiency-enhancing interfacial layer (1) and as a hole transport layer in photovoltaic (2) and dye sensitized solar cells (3). $\mathrm{NiO}$ is also antiferromagnetic with a high Néel temperature of $523 \mathrm{~K}(4-6)$, making it a strong candidate for spintronic devices. Photoexcitation of NiO can invoke a ferromagnetic response (5-8), and alter its insulatorlike properties on ultrafast timescales (9). Ultimately, the timescale that $\mathrm{NiO}$ redistributes photoexcitation and the related mechanism of local rearrangement of $3 d$-electrons dictate its activity in solar cell applications and its efficiency as opto-electronic and opto-magnetic devices.

$\mathrm{Ni}$ has the lowest excitation energy of the first-row transition metal elements and an open $3 d$ subshell, providing an extremely rich density of states. This enables electron-electron (e-e) scattering to be a prominent relaxation mechanism in bulk $\mathrm{NiO}$, leading to excited state dynamics as short as $10 \mathrm{~s}$ of fs $(7,10)$ or self-trapped electrons via formation of polarons on the sub-ps timescale (11). The $d^{8}$ ground state electron configuration of $\mathrm{NiO}$ formally consists of fully occupied $\mathrm{t}_{2 \mathrm{~g}}$ and halffilled $e_{g}$ orbitals, with strong hybridization between the $2 p$ and
$3 \mathrm{~d}$ bands (7). The $\mathrm{d}$-shell of $\mathrm{Ni}$ is the most compact of all transition metals (12), enabling $\mathrm{NiO}$ to contain signatures of both localized atomic-like states and band-like dispersive electronic states. $\mathrm{NiO}$ is classified as an intermediate charge-transfer insulator, suggesting that the charge transfer energy gap $(\Delta)$ between the $0-2 p$ band and the unoccupied Hubbard band, is smaller than the weakly screened Coulomb interaction (Hubbard U) (7), thereby leaving O-2p bands in the energy range of the occupied Hubbard band. Although the commonly reported band gap of $\mathrm{NiO}$ is 4.1-4.3 eV $(8,9)$, the onset of its photoabsorption has been recorded as low as $3.1 \mathrm{eV}(13)$. This lower energy feature is often ignored, but has been identified as excitation between the valence $\mathrm{Ni}-3 \mathrm{~d}$ and the $\mathrm{Ni}-4 \mathrm{~s}$ character of the conduction band minima (13). Detailed calculations provide mounting support for the importance of such s character states, which are more delocalized $(14,15)$. This challenges conventional knowledge which considers only localized $3 \mathrm{~d}\left(\mathrm{e}_{\mathrm{g}}\right)$ states in the conduction band edge and suggests that the photodynamics of $\mathrm{NiO}$ materials are influenced by the involvement of different electronic orbitals.

Sub-nanometer clusters are the ideal venue for identifying the electronic and structural factors that govern carrier dynamics and related excited state lifetimes (16-18). Their electronic properties change with the addition or subtraction of a single atom and their finite size is completely addressable by density functional theory (DFT), enabling detailed insights about the role of defect sites in bulk-scale reactions. Nickel oxide clusters are among the least understood transition metal oxides and are also the most intriguing because they contain a high number of energetically competitive structural isomers and spin configurations. Here, femtosecond pump-probe spectroscopy 
coupled with theoretical calculations are used to show a unique reliance on the $\mathrm{Ni}$ orbital contributions to the photoexcited neutral nickel oxide cluster lifetimes, and by extension allow for a deeper understanding of the bulk-scale photoexcitation. Specifically, ligand-to-metal charge transfer (LMCT) excitations undergo rapid relaxation through e-e scattering. The introduction of $\mathrm{O}$ vacancies enables $\mathrm{Ni}-3 \mathrm{~d} \rightarrow \mathrm{Ni}-4 \mathrm{~s}$ transitions and $\mathrm{Ni}-3 \mathrm{~d} \rightarrow \mathrm{Ni}-4 \mathrm{p}$ transitions that exhibit delocalized carriers and slower relaxation dynamics. We demonstrate these intriguing effects by adjusting the electronic structure of clusters with atomic precision.

\section{RESULTS AND DISCUSSION}

Neutral nickel oxide clusters are produced using a laser vaporization source and their excited states are subsequently measured through the pump-probe technique, where ionization enables for detection through mass spectrometry. The cluster distribution is presented in SI Fig. S1. DFT calculations are performed to relate the experimental lifetimes to the electronic properties of each cluster. Our calculated structures of nickel oxide clusters are in agreement with previous calculations (19, $20)$, where $(\mathrm{NiO})_{2-5}$ clusters all form planar ring structures. Suboxides show strong $\mathrm{Ni}-\mathrm{Ni}$ bonding, with $\mathrm{O}$ atoms decorating the periphery of the cluster in hollow sites followed by bridging locations, avoiding $\mathrm{O}-\mathrm{O}$ bonding and terminal $\mathrm{O}$ sites. The optimized neutral cluster structures are presented next to their transient signals. Photoexcitation is characterized as the change in electron density on each of the Ni-3d, Ni-4s, Ni-4p, and $0-2 p$ orbitals.

The transients of the $(\mathrm{NiO})_{n}$ clusters $(n=1-5)$ all show a similar fast relaxation of $\sim 110$ fs following absorption of a single UV $(400 \mathrm{~nm}=3.1 \mathrm{eV})$ photon (Fig. 1). Our calculations (Table 1) reveal that in all cases, photoexcitation involves a transition from the $\mathrm{O}$ atoms to the $\mathrm{Ni}$ atoms in a LMCT. The electron density on the $\mathrm{Ni}$ atoms increases through photoexcitation and therefore exhibits a fast relaxation that is attributed to e-e scattering, similar to bulk NiO. The slightly longer lifetime of $\mathrm{NiO}$ over larger stoichiometric clusters is due to a lower density of states and degrees of freedom. The fraction of the excited state population $(\delta)$ that enters a long-lived (> $2.5 \mathrm{ps}$ ) state, determined by the amplitude ratio of the fitting coefficients between the plateau function and total transient signal, reveals a decrease in the long-lived component with size of stoichiometric cluster (Table 1$)$. A long-lived state is accessible in $\mathrm{NiO}(\delta=18 \%)$ and $(\mathrm{NiO})_{2}(\delta=2.0 \%)$ but is not in larger clusters. The decreasing plateau component of the transient signal suggests that the larger clusters contain sufficiently high density of states to enable charge recombination. The potential energy curves of $\mathrm{NiO}$ reveal a rich density of excited states below the $\mathrm{X}^{3} \Sigma^{-} \rightarrow{ }^{3} \Sigma^{-}$photoexcitation at $3.04 \mathrm{eV}$ (21). Photoelectron spectroscopy (PES) of $\mathrm{NiO}$ shows several low-lying excited states below $3 \mathrm{eV}$ (22-25), and a $\sim 0.5 \mathrm{eV}$ energy gap between the ground and the first excited state $(21,26)$. Our measurements show the ${ }^{3} \Sigma$ state of $\mathrm{NiO}$ has a lifetime of $214 \pm 12 \mathrm{fs}$ and may cross into a long-lived ${ }^{3} \Sigma^{+}$or ${ }^{3} \Delta$ state, which is represented by the plateau function. This is in agreement with literature results, where lower lying excited states exhibit microsecond lifetimes following visible excitation (27). Perhaps unsurprisingly, the stoichiometric clusters exhibit the fastest lifetimes due to the LMCT placing more electron density on the $\mathrm{Ni}-3 \mathrm{~d}$ orbitals which relax through e-e scattering. These results echo the rapid relaxation dynamics reported for chromium oxide clusters, where the LMCT character of the excited state is proportional to the $10 \mathrm{~s}$ of $\mathrm{fs}$ relaxation through e-e scattering amongst the $d$ electrons (18). The e-e scattering mechanism is likely prominent in all open $d$-shell transition metal oxides, especially when LMCT occurs.

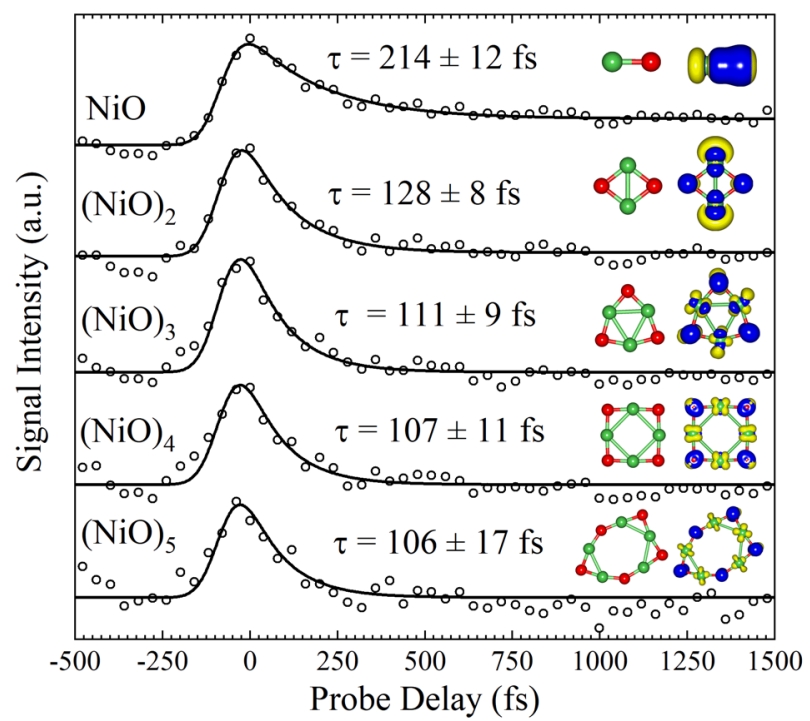

Fig. 1. The transient signal of $(\mathrm{NiO})_{n}(n=1-5)$ clusters with total fit shown in black and lifetime shown above each curve. TDDFT BPW91 transition densities are presented at an isodensity of $0.005 / \AA^{3}$. Electron densities are yellow, holes are blue, $\mathrm{Ni}$ atoms are green, and oxygen atoms are red.

Oxygen deficient clusters possess longer sub-ps lifetimes (Table 2). Suboxides have large proportions of $3 d \rightarrow 4 p$ photoexcitation which may be responsible for the long-lived states. The $\mathrm{Ni}_{2} \mathrm{O}_{x}(x<3)$ series reveals gradual changes in excited state transients with $\mathrm{O}$ content (Fig. 2). The density of states increases with $\mathrm{O}$ content facilitating a faster relaxation to the ground state.

Table 1. Excited state lifetimes ( $\tau$ ), long-lived percent population $(\delta)$, and changes in electron density for each atomic orbital for neutral $(\mathrm{NiO})_{n}$ clusters $(n=1-5)$.

\begin{tabular}{lcccccc}
\hline Cluster & \multirow{2}{*}{$\tau(\mathrm{fs})$} & $\delta(\%)$ & $\mathrm{Ni}-3 \mathrm{~d}$ & $\mathrm{Ni}-4 \mathrm{p}$ & $\mathrm{Ni}-4 \mathrm{~s}$ & $\mathrm{O}-2 \mathrm{p}$ \\
\hline $\mathrm{NiO}$ & $214 \pm 12$ & 18 & 3.5 & 3.1 & 0.00 & -6.5 \\
$(\mathrm{NiO})_{2}$ & $128 \pm 8$ & 2.0 & -61.5 & 14.9 & 65.9 & -28.6 \\
$(\mathrm{NiO})_{3}$ & $111 \pm 9$ & 0.0 & 15.2 & -6.0 & 28.4 & -37.6 \\
$(\mathrm{NiO})_{4}$ & $107 \pm 11$ & 0.0 & 24.3 & -6.3 & -2.9 & -20.6 \\
$(\mathrm{NiO})_{5}$ & $106 \pm 17$ & 0.0 & 39.2 & -5.1 & 42 & -77 \\
\hline
\end{tabular}


The transient signal for $\mathrm{Ni}_{2}$ requires a growth function $\left(\tau_{\mathrm{g}}\right)$ and shows the entire population reaches a long-lived (> $2.5 \mathrm{ps}$ ) state. The measured $\tau_{\mathrm{g}}(28 \pm 9 \mathrm{fs})$ matches the cross correlation of the laser beams, suggesting the signal arises from the direct ionization of $\mathrm{Ni}_{2}$ that is present in the neutral cluster population. The ground state of $\mathrm{Ni}_{2}$ has been investigated with controversial results that arise from the interaction of two $3 d^{9} 4 s^{1}$ $\mathrm{Ni}$ atoms, forming a single bond between the $4 \mathrm{~s}$ orbitals with little $3 d$ involvement. The electronically excited states are less characterized and difficult to assign, but appear at wavelengths $<450 \mathrm{~nm}$ (28). The $\mathrm{UV}$-vis spectra of $\mathrm{Ni}_{2}$ shows several absorption bands at $\sim 3 \mathrm{eV}(29,30)$. The $\mathrm{d} \sigma_{\mathrm{g}} \rightarrow \mathrm{p} \pi_{\mathrm{u}}\left({ }^{3} \pi_{\mathrm{u}}\right.$ or $\mathrm{C}$ state) is strongly bound, but overlaps with the dissociative $s \sigma_{\mathrm{g}}$ $\rightarrow \mathrm{s} \sigma_{\mathrm{u}}\left({ }^{3} \Sigma_{\mathrm{u}}{ }^{-}\right.$or B state) $(29,31) . A \mathrm{~d} \delta_{\mathrm{g}} \rightarrow \mathrm{p} \pi_{\mathrm{u}}$ transition $\left({ }^{3} \Phi_{\mathrm{u}}\right.$ state) may also exist nearby but is expected to have weak signal intensity. No decrease in the transient $\mathrm{Ni}_{2}{ }^{+}$signal is recorded, suggesting the $\mathrm{C}^{3} \pi_{\mathrm{u}}$ state of $\mathrm{Ni}_{2}$ is accessed by the 3.1 $\mathrm{eV}$ pump photon and is long lived due to poor overlap with lower lying states. Photoexcitation of $\mathrm{Ni}_{2}$ is strictly Ni-3d $\rightarrow$ $\mathrm{Ni}-4 \mathrm{p}$ in our calculations (SI Fig. S3). Thus, an electron is promoted from an essentially nonbonding 3d-type molecular orbital into a $4 \mathrm{p} \pi_{\mathrm{u}}$ orbital, with some bonding character resulting in a stronger bond (32).

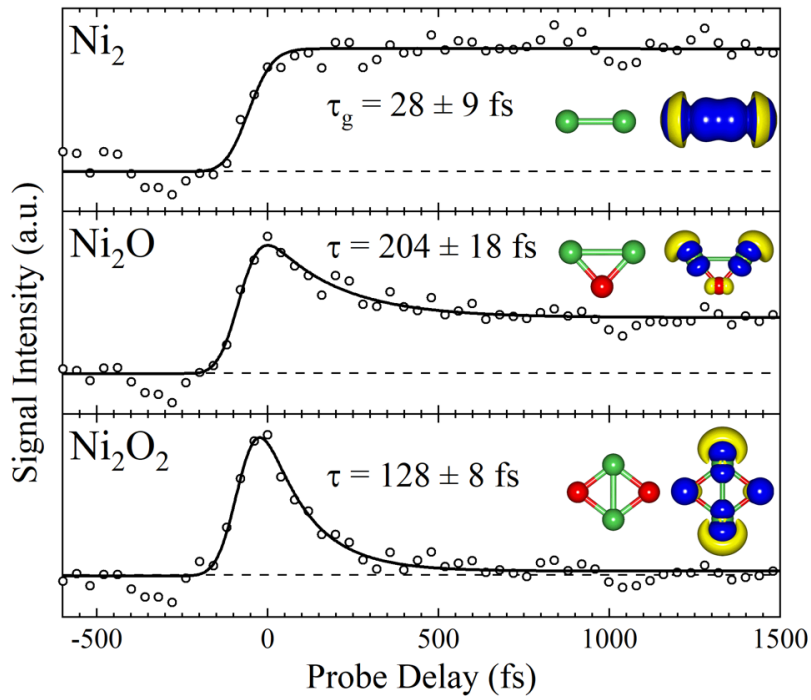

Fig. 2. The transient signals for $\mathrm{Ni}_{2} \mathrm{O}_{\mathrm{x}}(\mathrm{x}<3)$ clusters with total fit and lifetime shown. Dashed lines show the initial signal intensity. The structures and densities are similar to Fig.1, except $\mathrm{Ni}_{2}$ is shown at an isodensity of $0.002 / \AA^{3}$.

The density of states of $\mathrm{Ni}_{2} \mathrm{O}_{2}$ and $\mathrm{Ni}_{2} \mathrm{O}$ both demonstrate energy spacings of $\sim 0.5 \mathrm{eV}$ (SI Fig. S3) in agreement with previous calculations $(33,34)$. $\mathrm{Ni}_{2} \mathrm{O}^{+}$is a particularly stable cation (35) and a common photofragment (36). The transient signal for $\mathrm{Ni}_{2} \mathrm{O}$ contains a slower (204 $\pm 18 \mathrm{fs}$ ) relaxation, extended by $\sim 60 \%$ over $\mathrm{Ni}_{2} \mathrm{O}_{2}$ which contains a fast ( $\sim 128 \mathrm{fs}$ ) decay from high LMCT. A large proportion $(\delta=32 \%)$ of the photoexcited $\mathrm{Ni}_{2} \mathrm{O}$ population reaches a long-lived state which survives over $2.5 \mathrm{ps}$, proportional to the amount of $\mathrm{d} \rightarrow \mathrm{p}$ transition character. Breakdown of the Laporte selection rule occurs through strong hybridization of $\mathrm{Ni}-3 \mathrm{~d}$ and $\mathrm{O}-2 \mathrm{p}$ orbitals, with photoexcitation of $\mathrm{Ni}_{2} \mathrm{O}$ characterized by Ni-3d $\rightarrow 55 \% \mathrm{Ni}-4 \mathrm{~s}$ and $32 \% \mathrm{Ni}-4 \mathrm{p}$. The $4 \mathrm{~s}$ orbitals have favorable exchange interactions with the $\mathrm{Ni}-3 \mathrm{~d}$ electrons due to large spatial overlap and are therefore strongly coupled and enable rapid relaxation through scattering, although slightly slower than the LMCT dynamics of the stoichiometric clusters.

The $\mathrm{Ni}_{3} \mathrm{O}_{x}(\mathrm{x}<4)$ clusters behave similar to the $\mathrm{Ni}_{2} \mathrm{O}_{x}$ clusters in that the sub-ps transient lifetime and long-lived (>2.5 ps) excited state population increases with decreased $\mathrm{O}$ character (Fig. 3). $\mathrm{Ni}_{3} \mathrm{O}_{x}$ clusters also contain a large density of states, with no obvious energy gaps (SI Fig. S3). The stoichiometric cluster, $\mathrm{Ni}_{3} \mathrm{O}_{3}$, has the shortest lifetime of the series (111 \pm 9 $\mathrm{fs})$ and does not contain a long-lived plateau. With one less $\mathrm{O}$ atom, the lifetime of $\mathrm{Ni}_{3} \mathrm{O}_{2}$ (202 $\pm 23 \mathrm{fs}$ ) increases by $~ 80 \%$ over the stoichiometric cluster. The transient signals for the photoexcitation of $\mathrm{Ni}_{3} \mathrm{O}_{2}$ and $\mathrm{Ni}_{3} \mathrm{O}$ exhibit comparable lifetimes and $\delta$ coefficients, suggesting similar excited state landscapes. Our calculations reveal that photoexcitation of both clusters contain significant $\mathrm{Ni}-3 \mathrm{~d}$ to $\mathrm{Ni}-4 \mathrm{~s}$ and $\mathrm{Ni}-4 \mathrm{p}$ transitions. The $4 \mathrm{~s}$ component couples to the $3 \mathrm{~d}$ electrons for a rapid relaxation. Further, the $4 \mathrm{~s}$ character is larger than the $4 \mathrm{p}$ component, reflected by long-lived states that is 13 and $18 \%$ of the total population of the $\mathrm{Ni}_{3} \mathrm{O}_{2}$ and $\mathrm{Ni}_{3} \mathrm{O}$ clusters, respectively.

The excited states of $\mathrm{Ni}_{3}$ are similar to $\mathrm{Ni}_{2}(29,31)$, with $\mathrm{d} \pi_{\mathrm{g}} \rightarrow$ $\mathrm{p} \pi_{\mathrm{u}}$ (bound) and the slightly higher energy $\mathrm{s} \sigma_{\mathrm{u}} \rightarrow \mathrm{s} \sigma_{\mathrm{g}}$ (dissociative) transitions near $400 \mathrm{~nm}$. However, in contrast to $\mathrm{Ni}_{2}{ }^{+}$, the $\mathrm{Ni}_{3}{ }^{+}$signal in our experiment does not appear with the laser pulse but instead exhibits a delayed growth. This delayed transient response is a strong signature of ionization that competes with photodissociation. Several possibilities might account for the growth recorded in the $\mathrm{Ni}_{3}{ }^{+}$signal $\left(\tau_{\mathrm{g}}=170 \pm 51 \mathrm{fs}\right)$ as it matches closely with the decay lifetime for most clusters, including $\mathrm{Ni}_{3} \mathrm{O}$ ( $191 \pm 18 \mathrm{fs}$ ). Our calculations predict a bond dissociation energy of $4.2 \mathrm{eV}$ for $\mathrm{Ni}_{3} \mathrm{O}$, in agreement with literature values (37), suggesting that it is stable and does not release $\mathrm{O}$ to form $\mathrm{Ni}_{3}$. Photodissociation of $\mathrm{Ni}_{3} \mathrm{O}_{2}$ to form $\mathrm{Ni}_{3}$ is also unlikely, requiring removal of two $\mathrm{O}$ atoms. However, $\mathrm{Ni}_{3}{ }^{+}$ is not observed from the photofragmentation of oxygen rich nickel oxide cation clusters (36) and $\mathrm{Ni}_{3}{ }^{+}$has a small fragmentation energy (38). Thus, it is likely that $\mathrm{Ni}_{3}$ dissociates from the combined energy of both laser beams at temporal overlap, through the dissociative $s \sigma_{\mathrm{u}} \rightarrow \mathrm{s} \sigma_{\mathrm{g}}$ excitation channel. This intermediate neutral state crosses into the stable $\mathrm{d} \pi_{\mathrm{g}} \rightarrow \mathrm{p} \pi_{\mathrm{u}}$ channel in $\sim 170 \mathrm{fs}$ where it remains for the duration of the experiment $(2.5 \mathrm{ps})$. Ionization then proceeds through the removal of the excited nonbonding d electron, resulting in a stable cation. 


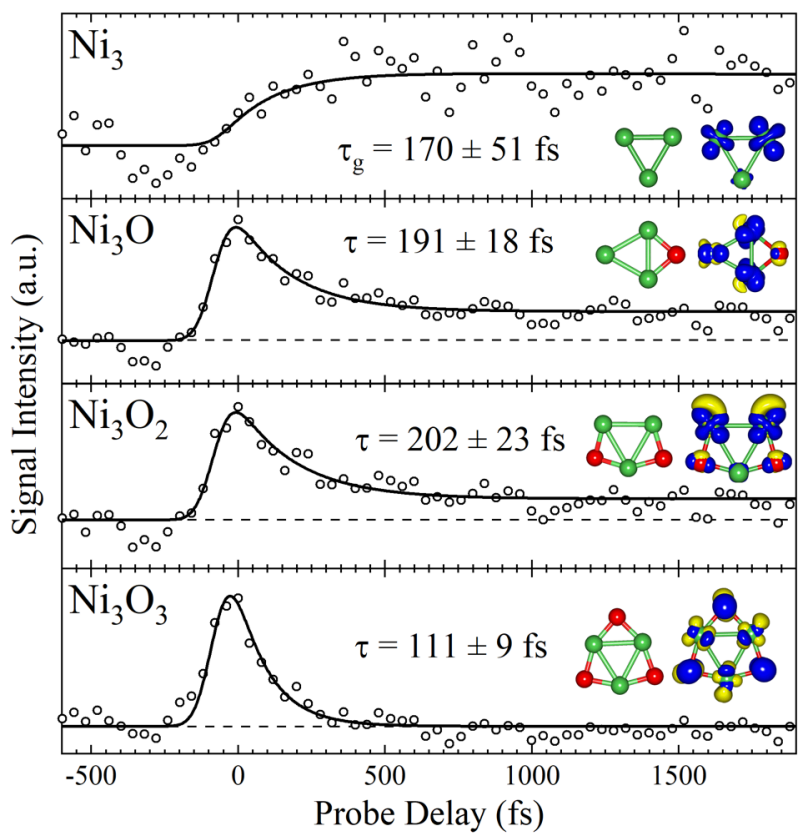

Fig. 3. The transient signal of $\mathrm{Ni}_{3} \mathrm{O}_{\mathrm{x}}(\mathrm{x}<4)$ clusters and their structures, similar to Fig. 1.

Clusters containing either 4 or $5 \mathrm{Ni}$ atoms continue to follow the described trend, where the stoichiometric clusters exhibit the fastest relaxation ( $\tau \sim 107 \mathrm{fs}$ ) through LMCT, and inclusion of oxygen defect sites enable longer lifetimes. With one less $\mathrm{O}$ atom from $\mathrm{Ni}_{4} \mathrm{O}_{4}$, the lifetime increases by $65 \%$ (Fig. 4). The photoexcitation of $\mathrm{Ni}_{4} \mathrm{O}_{3}$ and $\mathrm{Ni}_{4} \mathrm{O}_{2}$ contain similar $\mathrm{Ni}-\mathrm{d} \rightarrow \mathrm{Ni}-\mathrm{S}$ and $\mathrm{Ni}-\mathrm{d} \rightarrow \mathrm{Ni}-\mathrm{p}$ character, facilitating similar extended excited state lifetimes ( $\tau \sim 180 \mathrm{fs}$ ). Similarly, $\mathrm{Ni}_{5} \mathrm{O}_{3}$ and $\mathrm{Ni}_{5} \mathrm{O}_{4}$ contain similar dynamics, with lifetimes slightly longer than $\mathrm{Ni}_{5} \mathrm{O}_{5}$. The charge transfer of these clusters shows similar effects, where the $\mathrm{Ni}_{5} \mathrm{O}_{3}$ and $\mathrm{Ni}_{5} \mathrm{O}_{4}$ clusters are strongly $\mathrm{Ni}-\mathrm{d} \rightarrow \mathrm{Ni}$-s. Thus, in the $3 \mathrm{D}$ geometry of such larger clusters, the $\mathrm{Ni}-4 \mathrm{p}$ character of the excited electron becomes negligible, and no long-lived signal is obtained, demonstrating an efficient charge relaxation (SI Fig. S2).

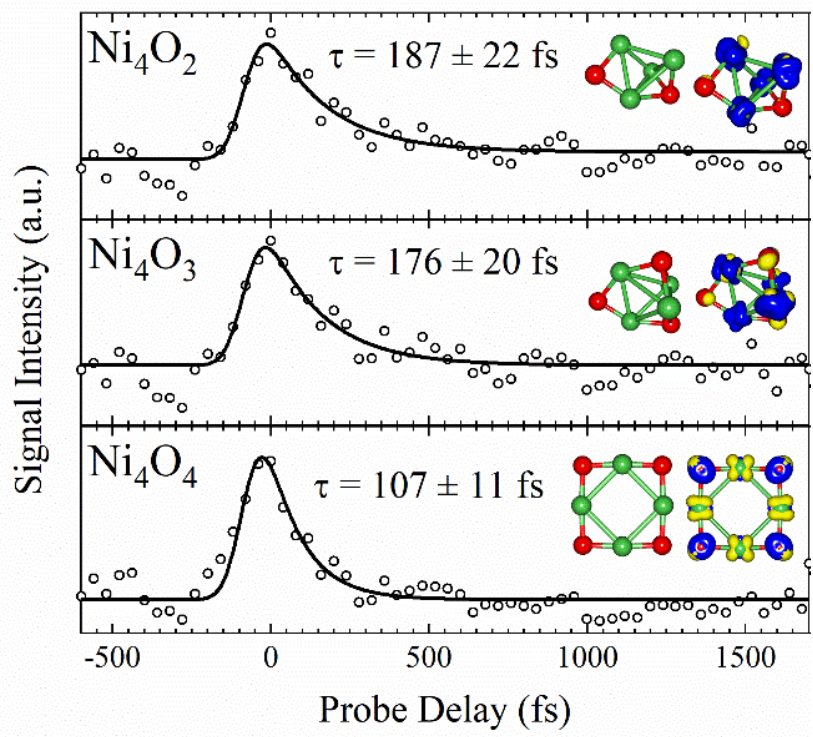

Fig. 4. The transient signal of $\mathrm{Ni}_{4} \mathrm{O}_{\mathrm{x}}(\mathrm{x}<4)$ clusters and their structures, similar to Fig. 1.

Stoichiometric clusters are not recorded with significant inten-

Table 2. Excited state lifetimes $(\tau)$, long-lived percent population $(\delta)$, and changes in electron density for each atomic orbital of suboxide neutral nickel oxide clusters.

\begin{tabular}{lcccccc}
\hline Cluster & $\tau(\mathrm{fs})$ & $\delta(\%)$ & $\mathrm{Ni}-3 \mathrm{~d}$ & $\mathrm{Ni}-4 \mathrm{p}$ & $\mathrm{Ni}-4 \mathrm{~s}$ & $\mathrm{O}-2 \mathrm{p}$ \\
$\mathrm{Ni}_{2}$ & $28 \pm 9^{*}$ & 100 & -96.8 & 96.8 & 0.0 & - \\
$\mathrm{Ni}_{2} \mathrm{O}$ & $204 \pm 18$ & 32 & -95.1 & 31.7 & 54.8 & 8.6 \\
$\mathrm{Ni}_{3}$ & $170 \pm 51^{*}$ & 100 & -92.2 & 92.2 & 0.0 & - \\
$\mathrm{Ni}_{3} \mathrm{O}$ & $191 \pm 18$ & 18 & -57.0 & 25.3 & 28.2 & 2.8 \\
$\mathrm{Ni}_{3} \mathrm{O}_{2}$ & $202 \pm 23$ & 13 & -17 & 3.0 & -6.3 & 20.3 \\
$\mathrm{Ni}_{4} \mathrm{O}_{2}$ & $187 \pm 22$ & 4.0 & -64.7 & 19.3 & 39 & 3 \\
$\mathrm{Ni}_{4} \mathrm{O}_{3}$ & $176 \pm 20$ & 0.0 & -71.2 & 24.1 & 35.2 & 8.8 \\
$\mathrm{Ni}_{5} \mathrm{O}_{3}$ & $117 \pm 20$ & 0.0 & -70.9 & 17.1 & 41.7 & 4.2 \\
$\mathrm{Ni}_{5} \mathrm{O}_{4}$ & $151 \pm 20$ & 0.0 & -54.4 & 4.2 & 42.5 & -14.6 \\
$\mathrm{Ni}_{6} \mathrm{O}_{4}$ & $225 \pm 40$ & 0.0 & -59.2 & 5.1 & 39.1 & -13.6 \\
$\mathrm{Ni}_{6} \mathrm{O}_{5}$ & $173 \pm 23$ & 0.0 & -12.5 & -1.6 & 5.7 & 10.1 \\
$\mathrm{Ni}_{7} \mathrm{O}_{5}$ & $167 \pm 36$ & 0.0 & -20.8 & 0 & 15.3 & -7.6 \\
$\mathrm{Ni}_{7} \mathrm{O}_{6}$ & $142 \pm 23$ & 0.0 & -20.3 & 1.4 & 6.5 & 4.6 \\
\hline *Indicates growth lifetime instead of decay & & & & \\
\hline
\end{tabular}

sity above $(\mathrm{NiO})_{5}$, however, the similar lifetime values and dynamics measured for a few additional suboxide clusters implies that the trend extends into larger clusters as well. The $\mathrm{d} \rightarrow \mathrm{p}$ transition is also not prominent in larger clusters, which instead show mainly a transition of $\mathrm{Ni}-3 \mathrm{~d} \rightarrow \mathrm{Ni}-4 \mathrm{~s}$ character. $\mathrm{Ni}_{6} \mathrm{O}_{4}$ has an unusually long lifetime compared to the other clusters (225 $\pm 40 \mathrm{fs}$ ). This extended lifetime may be related to its uniquely high $\mathrm{C}_{3}$ symmetry, which has also been suggested to be $T_{d}(19)$, which may facilitate the delocalization of charge carriers for a 
prolonged lifetime. Photoexcitation of $\mathrm{Ni}_{6} \mathrm{O}_{4}$ also contains significant Ni-3d $\rightarrow$ O-s character (up to 0.29 ), which is not present in other cluster excitations. The $\mathrm{Ni}_{7} \mathrm{O}_{5}$ and $\mathrm{Ni}_{7} \mathrm{O}_{6}$ clusters have lifetimes $\sim 29-52 \%$ greater than the expected stoichiometric lifetime of $110 \mathrm{fs}$, consistent with smaller cluster species. The transient signals for these larger clusters are presented in the SI (Fig. S2).

\section{CONCLUSION}

Neutral gas-phase nickel oxide clusters were produced using laser ablation and the femtosecond response to two-color pump-probe photoexcitation was measured. The sub-ps lifetimes of photoexcited states change for each cluster and depend upon the nature of the atomic orbitals involved. The stoichiometric $(\mathrm{NiO})_{n}$ clusters $(n<6)$ possess the shortest lifetimes ( 110 fs) which are attributed to a LMCT and subsequent e-e scattering, similar to bulk-scale material lifetimes. Thus, electron scattering is a prominent relaxation mechanism in strongly correlated transition metal oxide clusters. This timeresolved experiment on neutral nickel oxide clusters suggests $O$ vacancies slow relaxation by involving different atomic orbitals through photoexcitation. Decreased $\mathrm{O}$ content extends the sub-ps lifetime by up to $80 \%$ and allows for charge-trapping (long-lived state) through an increased $\mathrm{Ni} d \rightarrow p$ transition character. Detailed analysis of the atomic character of the photoexcitation indicates the participation of $\mathrm{Ni}-4 \mathrm{~s}$ orbitals are important in the ultrafast dynamics of $\mathrm{NiO}$ at the molecular scale. By extension, $\mathrm{s}$ character states cannot be ignored in the conduction band minima of bulk $\mathrm{NiO}$ and may be employed for extending excited state lifetimes and are therefore essential to the creation of advanced nickel oxide materials that facilitate magnetic and chemical transformations.

\section{METHODS}

\subsection{EXPERIMENTAL MEASUREMENTS}

Experimental measurements were carried out using a homebuilt Wiley-McLaren (39) type time-of-flight mass spectrometer (TOFMS) discussed in detail previously (16). Briefly, a pulsed Nd:YAG laser was used for ablation of a pure 1/4" nickel rod under high vacuum conditions ( $7.5 \times 10^{-8}$ Torr). The plasma plume was directed by expansion of a seeded He gas pulse $\left(1 \% \mathrm{O}_{2}\right)$, confined to a $1 \times 60 \mathrm{~mm}$ collision region, and skimmed to a collimated molecular beam diameter of $2 \mathrm{~mm}$. All cations and anions were deflected from the beam prior to ionization of the neutral molecular beam by charging the skimmer to $+500 \mathrm{~V}$. Neutral clusters were ionized by a sequence of sub-35 fs laser pulses from a Ti:Sapphire laser and accelerated by a $\sim 4 \mathrm{kV}$ pulsed electric field. The clusters were focused onto the detector (MCP) using an Einzel lens and separated in time as they traversed a $1.5 \mathrm{~m}$ field-free region. The second harmonic of the laser $(400 \mathrm{~nm}, 3.1 \mathrm{eV})$ was separated from the fundamental $800 \mathrm{~nm}(1.55 \mathrm{eV})$ laser, which traversed a programmed delay-stage before recombining the beams. The 800 $\mathrm{nm}$ (probe) beam was temporally scanned in $40 \mathrm{fs}$ increments from -600 to $2500 \mathrm{fs}$ relative to the $400 \mathrm{~nm}$ (pump) beam.
Excitation is achieved with a single pump photon and ionization occurs through absorption of multiple probe photons. An average of 500 spectra were recorded for each time delay. The excited state transient signals of neutral nickel oxide clusters are recorded by scanning the optical delay of the probe beam with respect to the pump pulse and tracking the change of intensity from each ion signal. The ion signal is proportional to the excited state population as it decays in time. The instrumental response function is determined to be $<35 \mathrm{fs}$ using the $\mathrm{O}_{2}$ cross correlation ionization signal. An exponential decay function and a plateau function is used to fit all cluster transients, described in detail previously $(16,17)$. The measured lifetime $(\tau)$ provides the relaxation lifetime to the ground state of the neutral cluster and the plateau function represents a stable long-lived (>2.5 ps) excited state that survives longer than the experiment. All spectra were recorded using $7.92 \times 10^{14}$ $\mathrm{W} / \mathrm{cm}^{2} 400 \mathrm{~nm}$ pump and $1.62 \times 10^{15} \mathrm{~W} / \mathrm{cm}^{2} 800 \mathrm{~nm}$ probe pulses.

\subsection{COMPUTATIONAL METHOD}

Calculations relate the experimental lifetimes to the electronic properties of each cluster. Due to the accuracy demonstrated by BPW91 previously for both nickel and nickel oxide clusters, and for both low computational cost and high speed, we rely on the GGA functional BPW91 to calculate the nickel oxide clusters. Often BPW91 performs better than B3LYP for describing magnetic properties because the XC functional LYP does not have equal spin correlation and exaggerates the oppositespin correlation (40), which plays a strong role in the high spin structures of the nickel oxide clusters. Calculations were performed using the 6-311g+* basis set, namely (15s11p6d1f/10s7p4d1f) for $\mathrm{Ni}$ and $(12 \mathrm{~s} 6 \mathrm{p} 1 \mathrm{~d} / 5 \mathrm{~s} 4 \mathrm{p} 1 \mathrm{~d})$ for $\mathrm{O}$ atoms. The minimum state geometries were used as input for single point time dependent-density functional theory (TDDFT) calculations to account for the excited state characteristics. An excited state population analysis was performed to determine the elemental contributions to the excited state. The excited state orbital transfer character for all clusters are presented in SI Fig. S3-S6.

\section{SUPPORTING INFORMATION}

See supplemental material for the experimental cluster distribution, lifetime measurements for larger $\mathrm{Ni}_{n} \mathrm{O}_{n-\mathrm{x}}(\mathrm{n}=5-7, \mathrm{x}<3)$ clusters, calculated excited state orbital contributions for all excited states, and cluster spin states and structures.

\section{CORRESPONDING AUTHOR}

*Scott.Sayres@asu.edu

\section{AUTHOR CONTRIBUTIONS}

S.G.S and J.M.G. designed the experiments. J.M.G. performed the ultrafast pump-probe spectroscopy, and S.G.S and J.M.G wrote the paper.

\section{Acknowledgements}


We gratefully acknowledge support from ASU Lightworks. J.G also acknowledges support from Western Alliance to Expand Student Opportunities (WAESO) Louis Stokes Alliance for Minority Participation (LSAMP) Bridge to Doctorate (BD) National Science Foundation (NSF) Grant No. HRD-1702083.

\section{REFERENCES}

1. M. D. Irwin, D. B. Buchholz, A. W. Hains, R. P. H. Chang, T. J. Marks, p-Type semiconducting nickel oxide as an efficiencyenhancing anode interfacial layer in polymer bulk-heterojunction solar cells. Proc. Natl. Acad. Sci. 105, 2783-2787 (2008).

2. A. Corani, et al., Ultrafast Dynamics of Hole Injection and Recombination in Organometal Halide Perovskite Using Nickel Oxide as p-Type Contact Electrode. J. Phys. Chem. Lett. 7, 10961101 (2016).

3. R. J. Dillon, L. Alibabaei, T. J. Meyer, J. M. Papanikolas, Enabling Efficient Creation of Long-Lived Charge-Separation on Dye-Sensitized NiO Photocathodes. ACS Appl. Mater. Interfaces 9, 26786-26796 (2017).

4. L. Huber, et al., Coherent acoustic perturbation of secondharmonic generation in NiO. Phys. Rev. B - Condens. Matter Mater. Phys. 92, 94304 (2015).

5. M. Fiebig, et al., Ultrafast magnetization dynamics of antiferromagnetic compounds. J. Phys. D. Appl. Phys. 41, 164005 (2008).

6. M. Fiebig, N. P. Duong, T. Satoh, T. Lottermoser, Ultrafast and magnetoelectric phase transitions in antiferromagnets. J. Magn. Magn. Mater. 300, e264-e269 (2006).

7. K. Gillmeister, et al., Ultrafast coupled charge and spin dynamics in strongly correlated NiO. Nat. Commun. 11 (2020).

8. R. Gómez-Abal, O. Ney, K. Satitkovitchai, W. Hübner, Alloptical subpicosecond magnetic switching in $\mathrm{NiO}(001)$. Phys. Rev. Lett. 92 (2004).

9. N. Tancogne-Dejean, M. A. Sentef, A. Rubio, Ultrafast transient absorption spectroscopy of the charge-transfer insulator $\mathrm{NiO}$ : Beyond the dynamical Franz-Keldysh effect. Phys. Rev. B 102, 115106 (2020).

10. K. Gillmeister, M. Kiel, W. Widdra, Image potential states at transition metal oxide surfaces: A time-resolved two-photon photoemission study on ultrathin NiO films. Phys. Rev. B 97, 110 (2018).

11. S. Biswas, J. Husek, S. Londo, L. R. Baker, Ultrafast Electron Trapping and Defect-Mediated Recombination in NiO Probed by Femtosecond Extreme Ultraviolet Reflection-Absorption Spectroscopy. J. Phys. Chem. Lett. 9, 5047-5054 (2018).

12. E. J. Friedman-Hill, R. W. Field, Analysis of the $[16.0]^{3} \Sigma^{-}-X^{3} \Sigma$ and $[16.0]^{3} \Sigma^{-}-[4.3]^{3} \Pi_{\mathrm{i}}$ band systems of the $\mathrm{NiO}$ molecule. J. Mol. Spectrosc. 155, 259-276 (1992).

13. J. L. Li, G. M. Rignanese, S. G. Louie, Quasiparticle energy bands of $\mathrm{NiO}$ in the GW approximation. Phys. Rev. B - Condens. Matter Mater. Phys. 71, 1-4 (2005).

14. N. Alidoust, M. C. Toroker, E. A. Carter, Revisiting photoemission and inverse photoemission spectra of nickel oxide from first principles: Implications for solar energy conversion. $J$. Phys. Chem. B 118, 7963-7971 (2014).

15. Y. Gao, et al., Electronic structure of bulk manganese oxide and nickel oxide from coupled cluster theory. Phys. Rev. B 101, 1-9 (2020).

16. J. M. Garcia, R. E. Shaffer, S. G. Sayres, Ultrafast pump-probe spectroscopy of neutral $\mathrm{Fe}_{\mathrm{n}} \mathrm{O}_{\mathrm{m}}$ clusters $(\mathrm{n}, \mathrm{m}<16)$. Phys. Chem. Chem. Phys. 22, 24624-24632 (2020).

17. J. M. Garcia, L. F. Heald, R. E. Shaffer, S. G. Sayres, Oscillation in Excited State Lifetimes with Size of Sub-nanometer Neutral $\left(\mathrm{TiO}_{2}\right)_{\mathrm{n}}$ Clusters Observed with Ultrafast Pump-Probe Spectroscopy. J. Phys. Chem. Lett. 12, 4098-4103 (2021).

18. J. M. Garcia, S. G. Sayres, Increased Excited State Metallicity in Neutral $\mathrm{Cr}_{2} \mathrm{O}_{n}$ Clusters $(\mathrm{n}<5)$ upon Sequential Oxidation. J. Am.
Chem. Soc. 143, 15572-15575 (2021).

19. R. H. Aguilera-Del-Toro, F. Aguilera-Granja, L. C. Balbás, A. Vega, Structure, fragmentation patterns, and magnetic properties of small nickel oxide clusters. Phys. Chem. Chem. Phys. 19, 3366-3383 (2017).

20. G. L. Gutsev, K. G. Belay, K. V. Bozhenko, L. G. Gutsev, B. R. Ramachandran, A comparative study of small 3d-metal oxide $(\mathrm{FeO})_{\mathrm{n}},(\mathrm{CoO})_{\mathrm{n}}$, and $(\mathrm{NiO})_{\mathrm{n}}$ clusters. Phys. Chem. Chem. Phys. 18, 27858-27867 (2016)

21. S. P. Walch, G. I. W.A., Electronic States of the NiO Molecule. J. Am. Chem. Soc. 100, 1338-48 (1978).

22. H. Wu, L. S. Wang, A study of nickel monoxide (NiO), nickel dioxide $(\mathrm{ONiO})$, and $\mathrm{Ni}\left(\mathrm{O}_{2}\right)$ complex by anion photoelectron spectroscopy. J. Chem. Phys. 107, 16-21 (1997).

23. O. Tjernberg, G. Chiaia, U. O. Karlsson, F. M. F. De Groot, Resonant photoelectron spectroscopy on CoO. J. Phys. Condens. Matter 9, 9863-9871 (1997).

24. J. Ho, M. L. Polak, K. M. Ervin, W. C. Lineberger, Photoelectron spectroscopy of nickel group dimers: $\mathrm{Ni}_{2}{ }_{2}, \mathrm{Pd}_{2}{ }_{2}$, and $\mathrm{Pt}_{2}{ }_{2}$. J. Chem. Phys. 99, 8542-8551 (1993).

25. T. M. M. Ramond, et al., Photoelectron Spectroscopy of Nickel, Palladium, and Platinum Oxide Anions. J. Mol. Spectrosc. 216, 1-14 (2002).

26. V. D. Moravec, C. C. Jarrold, Study of the low-lying states of $\mathrm{NiO}^{-}$and NIO using anion photoelectron spectroscopy. J. Chem. Phys. 108, 1804-1810 (1998).

27. C. Qin, J. Zang, D. Zhang, Q. Zhang, Y. Chen, Laser-induced Fluorescence Spectroscopy of $\mathrm{NiO}$ between 510 and $650 \mathrm{~nm}$. Chinese J. Chem. Phys. 26, 512-518 (2013).

28. F. Ahmed, E. R. Nixon, The $\mathrm{A} \rightarrow \mathrm{X}$ system of $\mathrm{Ni}_{2}$ in argon matrices. J. Chem. Phys. 71, 3547-3549 (1979).

29. M. Moskovits, J. E. Hulse, The ultraviolet-visible spectra of diatomic, triatomic, and higher nickel clusters. J. Chem. Phys. 66, 3988-3994 (1977).

30. H. Wang, H. Haouari, R. Craig, J. R. Lombardi, D. M. Lindsay, Raman spectra of mass-selected nickel dimers in argon matrices. J. Chem. Phys. 104, 3420-3422 (1996).

31. A. B. Anderson, Theory of ultraviolet spectra for $\mathrm{Ni}_{2}$ and $\mathrm{Ni}_{3}$ and hypothesis for argon matrix frequency shifts for Ni atoms. $J$. Chem. Phys. 66, 5108-5111 (1977).

32. J. O. Noell, M. D. Newton, P. J. Hay, R. L. Martin, F. W. Bobrowicz, An ab initio study of the bonding in diatomic nickel. J. Chem. Phys. 73, 2360-2371 (1980).

33. W. Jin, C. Li, G. Lefkidis, W. Hübner, Laser control of ultrafast spin dynamics on homodinuclear iron- and nickel-oxide clusters. Phys. Rev. B - Condens. Matter Mater. Phys. 89, 1-7 (2014).

34. O. Hübner, H.-J. Himmel, MRCI investigation of $\mathrm{Ni}_{2} \mathrm{O}_{2}$ and $\mathrm{Ni}_{2} \mathrm{O}_{2}{ }^{+}$. Phys. Chem. Chem. Phys. 11, 2241 (2009).

35. D. Vardhan, R. Liyanage, P. B. Armentrout, Guided ion beam studies of the reactions of $\mathrm{Ni}_{n}{ }^{+}(\mathrm{n}=2-18)$ with $\mathrm{O}_{2}$ : Nickel cluster oxide and dioxide bond energies. J. Chem. Phys. 119, 4166-4178 (2003).

36. C. J. Dibble, S. T. Akin, S. Ard, C. P. Fowler, M. A. Duncan, Photodissociation of cobalt and nickel oxide cluster cations. $J$. Phys. Chem. A 116, 5398-5404 (2012).

37. D. Bandyopadhyay, Chemisorptions effect of oxygen on the geometries, electronic and magnetic properties of small size $\mathrm{Ni}_{\mathrm{n}}$ ( $\mathrm{n}=1-6)$ clusters. J. Mol. Model. 18, 737-749 (2012).

38. L. Lian, C. -X. Su, P. B. Armentrout, Collision-induced dissociation of $\mathrm{Ni}_{\mathrm{n}}^{+} \quad(\mathrm{n}=2-18)$ with $\mathrm{Xe}$ : Bond energies, geometrical structures, and dissociation pathways. J. Chem. Phys. 96, 7542-7554 (1992).

39. W. C. Wiley and I. H. McLaren, Time-of-Flight Mass Spectrometer with Improved Resolution. Rev. Sci. Instrum. 26, 1150-1157 (1955).

40. M. Filatov, D. Cremer, Calculation of spin-densities within the context of density functional theory. the crucial role of the correlation functional. J. Chem. Phys. 123, 1-7 (2005). 


\section{Significance}

A local rearrangement of the 3d-electrons plays a crucial role in many properties of strongly correlated transition metal oxide materials. Point defects, such as oxygen vacancies and their associated electrons, can lead to emergent phenomena. Among the most important physical properties of photoabsorption is photoexcited state lifetimes, where increases can facilitate catalytic transformation and magnetic manipulation. Here, we employ the atomic precision and tunability of gas phase clusters to reveal that changes to the character of the orbital of the photoexcited electron leads to vastly different relaxation dynamics. The $3 \mathrm{~d}$ to $4 \mathrm{~s}$ transition of $\mathrm{Ni}$ atoms relaxes rapidly through electron scattering, whereas $3 \mathrm{~d}$ to the delocalized $4 \mathrm{p}$ states of $\mathrm{Ni}$ enable long lived excited states. 


\section{Supplementary Information for}

\section{Orbital-Dependent Photodynamics of Strongly Correlated Clusters}

Jacob M. Garcia ${ }^{1,2}$ and Scott G. Sayres ${ }^{1,2^{*}}$

${ }^{1}$ School of Molecular Sciences, Arizona State University, Tempe, AZ 85287

${ }^{2}$ Biodesign Center for Applied Structural Discovery, Arizona State University, Tempe, AZ 85287

Scott G. Sayres

Email: scott.sayres@asu.edu

This PDF file includes:

Supplementary text

Figures S1 to S7

SI References 


\section{Supplementary Information Text}

\section{Cluster Distribution}

The prominent neutral clusters are the $\mathrm{Ni}_{n} \mathrm{O}_{\mathrm{n}-1}$ series from values of $\mathrm{n}<8$ and then $\mathrm{Ni}_{\mathrm{n}} \mathrm{O}_{\mathrm{n}}$ 2 for $\mathrm{n}>7$, consistent with previous experiments $(1,2)$. Stoichiometric clusters are only recorded for $\mathrm{n} \leq 5$. Minor signals from pure nickel clusters, $\mathrm{Ni}_{2}$ and $\mathrm{Ni}_{3}$, also appear in the neutral mass spectrum.

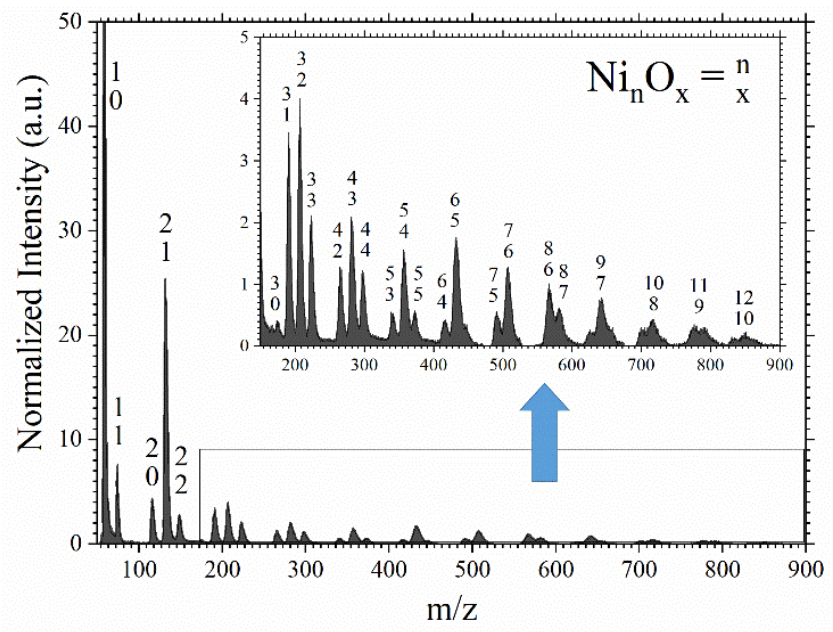

Fig. S1. Mass spectrum of neutral nickel oxide clusters following photoionization of the pump-probe pulse at temporal overlap. The inset is a zoomed in to show the distribution of the larger clusters. 
The excited state transients for larger clusters are shown in Fig. S2.

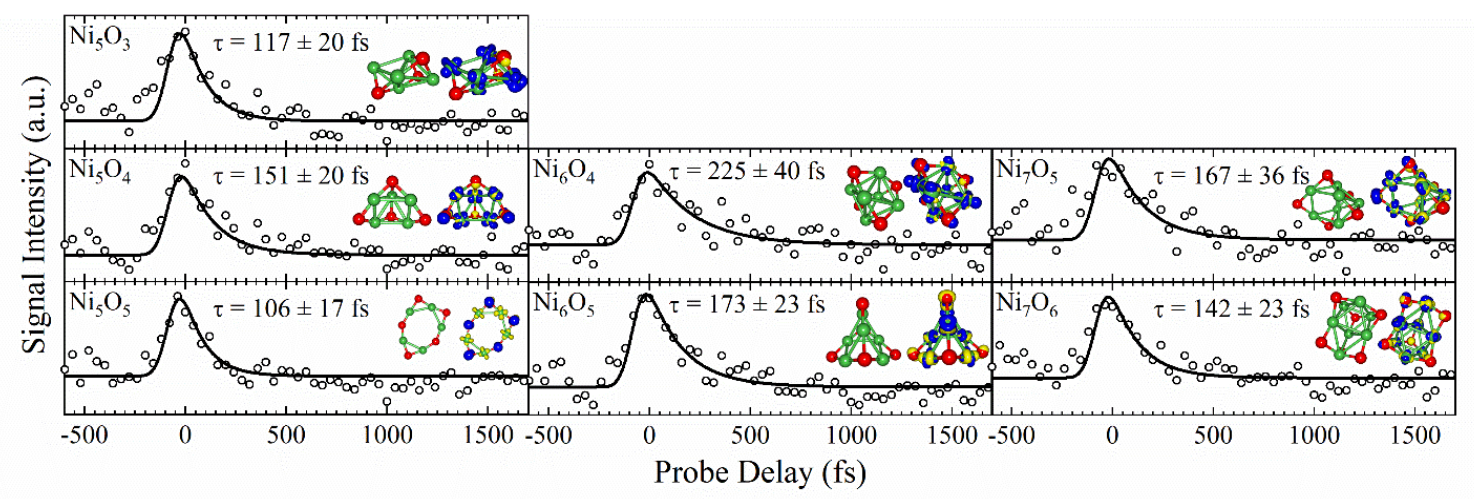

Fig. S2. The transients of the $\mathrm{Ni}_{5} \mathrm{O}_{x}, \mathrm{Ni}_{6} \mathrm{O}_{\mathrm{x}}$ and $\mathrm{Ni}_{7} \mathrm{O}_{\mathrm{x}}$ series showing the change in excitation lifetime as a result of oxidation. Total fit as a solid black line and lifetime $(\tau)$ above each transient. TD-DFT BPW91 transition densities are presented at an isodensity of $0.005 / \AA^{3}$. Electron densities are yellow, holes are blue, Ni atoms are green, and oxygen atoms are red. 


\section{Density of Excited States}

TD-DFT calculations were performed on the lowest energy configuration of each cluster, including a sufficient number of excited states to exceed the pump photon energy (400 nm $=3.1 \mathrm{eV}$ ). A population analysis was performed on the excited states to determine the charge transfer. The $c^{2}$ or $\mathrm{C}$-squared population analysis (CSPA) method disregards the fact that basis functions may overlap, and simply defines the contribution, $c_{a i}$, of a particular atomic orbital, $a$, to a particular molecular orbital, $i$, as the square of the molecular orbital coefficient normalized to the square of all atomic orbital coefficients, $\mathrm{k}$, as:

$$
\phi_{a i}=\frac{c_{a i}^{2}}{\sum_{k} c_{k i}^{2}}
$$

Several occupied virtual pairs contribute to a given TD-DFT excitation, and the contribution coefficient of each pair, $\mathrm{C}_{o v}$, is output by Gaussian16 (3). Figures S3-S6 show the overall change in electron density over the summation of the various atomic orbitals. It should be noted that the maximum total electron density transferred from a photoexcitation is 1 , but the linear combination of several occupied-virtual pairs that contribute to the photoexcitation can reduce this value. Thus, values less than 1 indicate conflict between orbital pairs (the individual excitations cancel one another for no net change between atomic orbitals), or excitation within the d-d orbitals occurs. The Ni-f, O-s, and O-d orbitals are involved in the calculation but do not compose a significant percentage of the charge transfer and so are not shown. $\mathrm{Ni}_{6} \mathrm{O}_{4}$ is unique in that it contains a signficant population of O-s orbitals. 

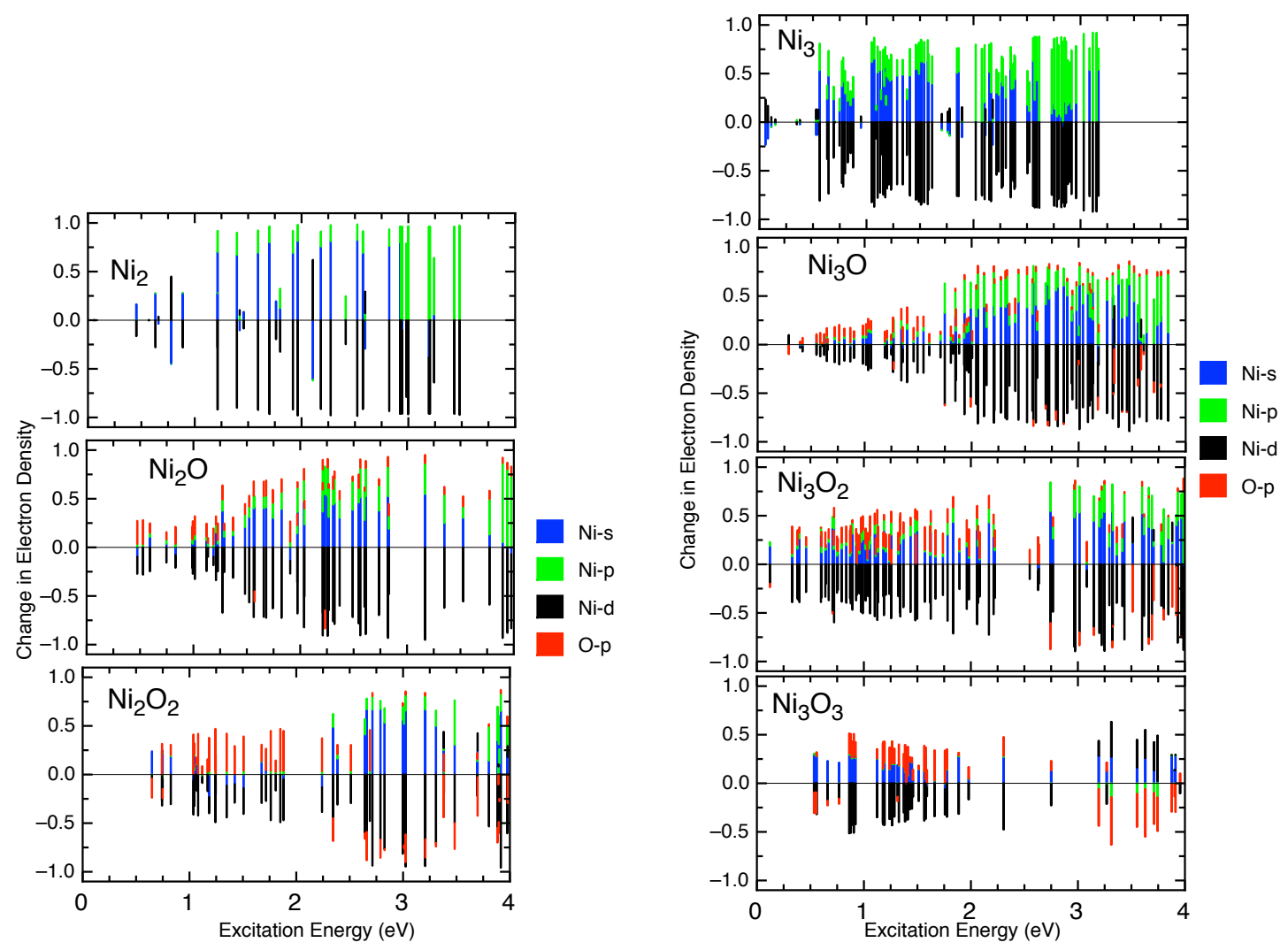

Fig. S3. C-squared population analysis of the TD-DFT excited states showing the density of states and change in electron density for the Ni-s, Ni-p, Ni-d, and Ni-p orbitals for each of the $\mathrm{Ni}_{2} \mathrm{O}_{\mathrm{x}}(\mathrm{x}<3)$ and $\mathrm{Ni}_{3} \mathrm{O}_{\mathrm{x}}(\mathrm{x}<4)$ clusters. 

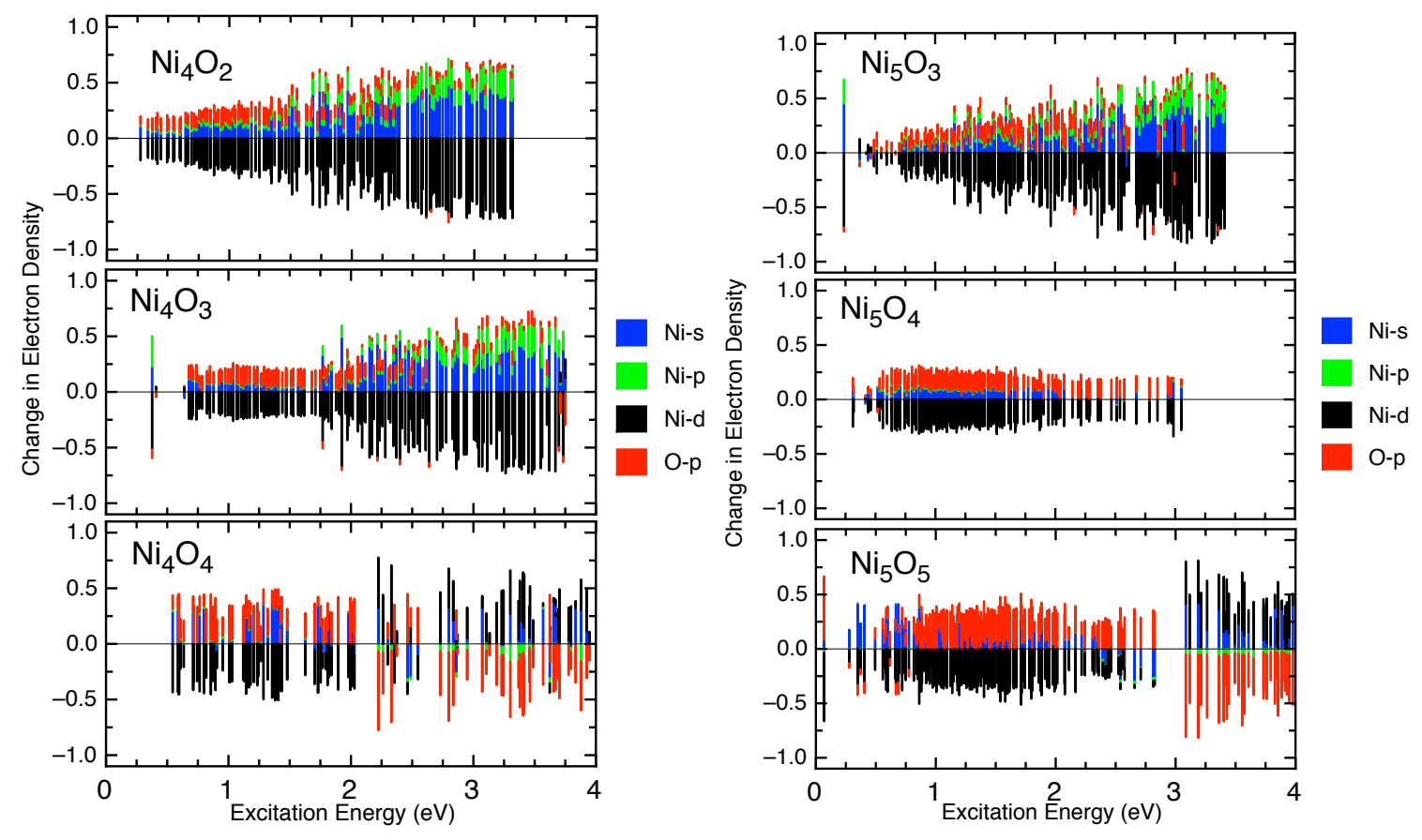

Fig. S4. C-squared population analysis of the TD-DFT excited states showing the density of states and change in electron density for the Ni-s, Ni-p, Ni-d, and Ni-p orbitals for each of the $\mathrm{Ni}_{4} \mathrm{O}_{\mathrm{x}}(\mathrm{x}=2,3,4)$ and $\mathrm{Ni}_{5} \mathrm{O}_{\mathrm{x}}(\mathrm{x} 3,4,5)$ clusters. 

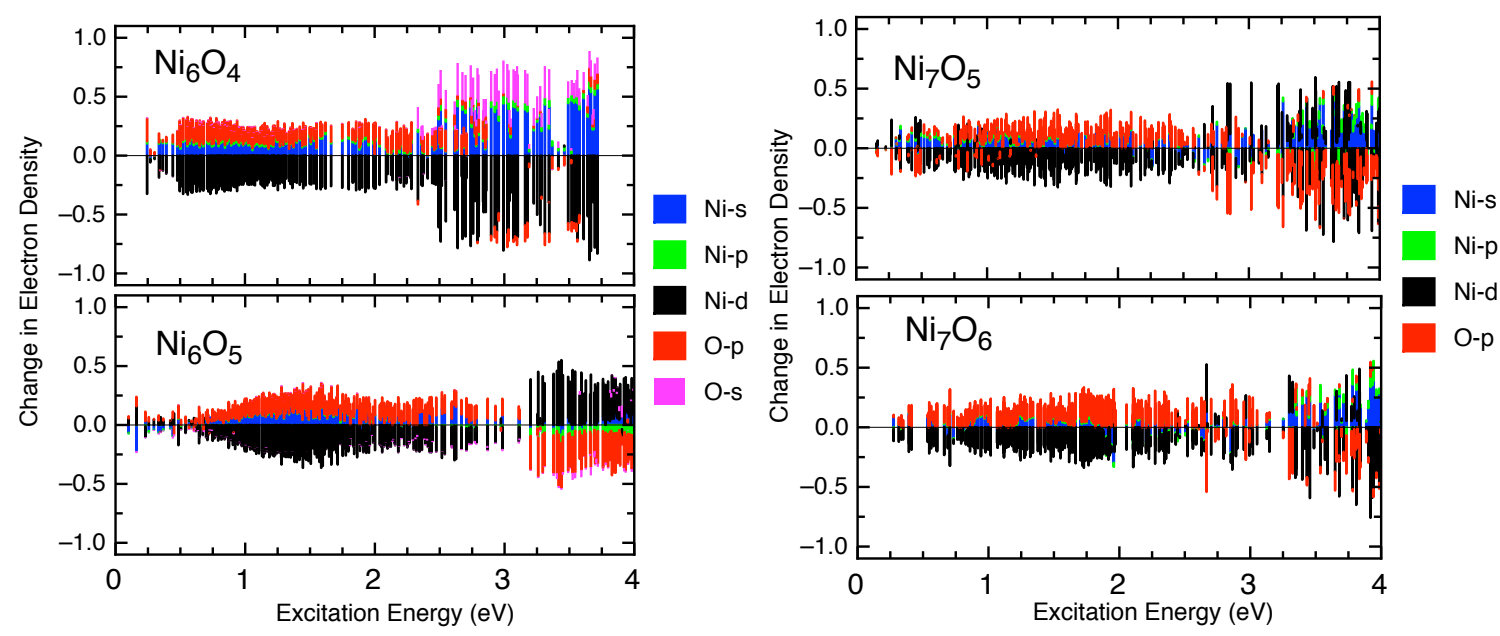

Fig. S5. C-squared population analysis of the TD-DFT excited states showing the density of states and change in electron density for the Ni-s, Ni-p, Ni-d, and Ni-p orbitals for each of the $\mathrm{Ni}_{6} \mathrm{O}_{\mathrm{x}}(\mathrm{x}=4,5)$ and $\mathrm{Ni}_{7} \mathrm{O}_{\mathrm{x}}(\mathrm{x}=5,6)$ clusters. 


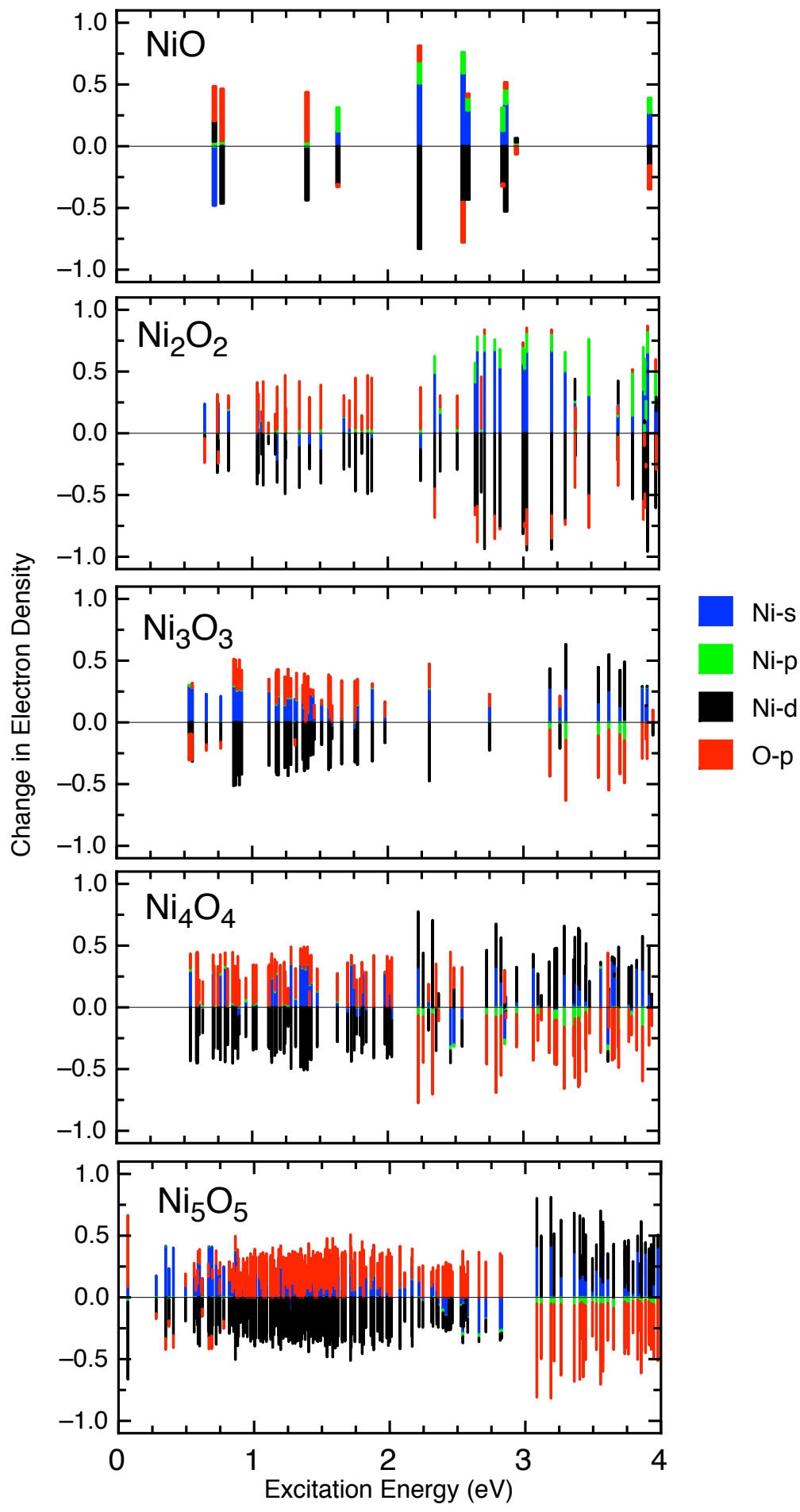

Fig. S6. C-squared population analysis of the TD-DFT excited states showing the density of states and change in electron density for the Ni-s, Ni-p, Ni-d, and Ni-p orbitals for each of the $(\mathrm{NiO})_{\mathrm{x}}(\mathrm{x}<6)$ clusters. 


\section{Cluster Structures and Spin states}

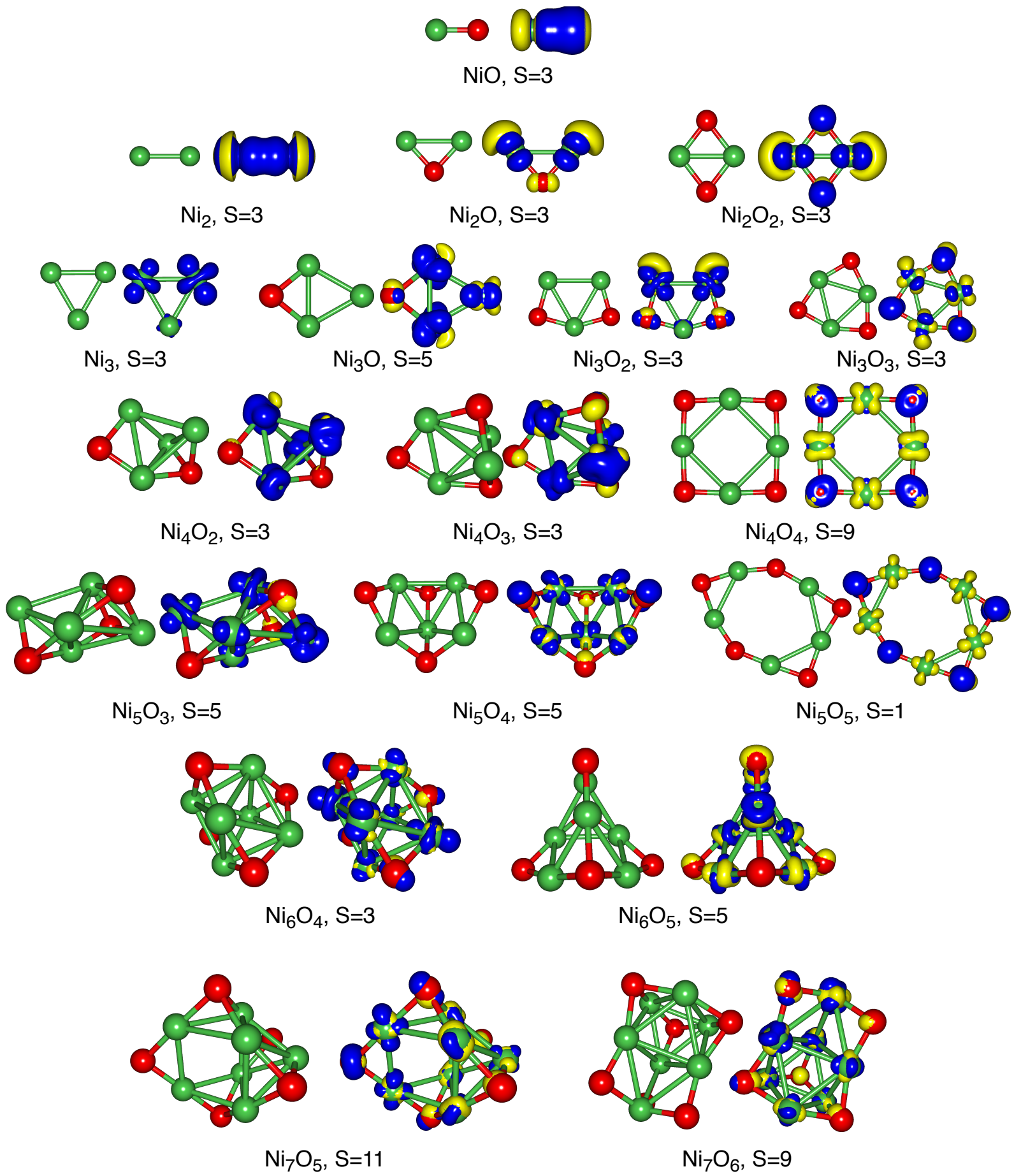

Fig. S7. TD-DFT BPW91 ground state structures and transition densities are presented at an isodensity of $0.005 / \AA^{3}$. Electron densities are yellow, holes are blue, $\mathrm{Ni}$ atoms are green, and oxygen atoms are red. Note: $\mathrm{Ni}_{2}$ is shown at an isodensity of $0.002 / \AA^{3}$ to show the diffuse electron 


\section{XYZ Coordinates}

Optimized xyz coordinates (and spin configurations) of nickel oxide clusters obtained at the ground state geometries using BPW91 (4) and standard 6-311G+(d) basis set.

\begin{tabular}{|c|c|c|c|}
\hline \multicolumn{4}{|c|}{$\mathrm{NiO}(2 \mathrm{~S}+1=3)$} \\
\hline $\mathrm{Ni}$ & 0.000000 & 0.000000 & 0.364260 \\
\hline $\mathrm{O}$ & 0.000000 & 0.000000 & -1.274911 \\
\hline \multicolumn{4}{|c|}{$(\mathrm{NiO})_{2}(2 \mathrm{~S}+1=3)$} \\
\hline $\mathrm{Ni}$ & 0.000000 & 1.085678 & -0.000030 \\
\hline $\mathrm{Ni}$ & -0.000000 & -1.085678 & -0.000030 \\
\hline $\mathrm{O}$ & -1.404125 & 0.000000 & 0.000105 \\
\hline $\mathrm{O}$ & 1.404125 & -0.000000 & 0.000105 \\
\hline \multicolumn{4}{|c|}{$(\mathrm{NiO})_{3}(2 \mathrm{~S}+1=3)$} \\
\hline $\mathrm{Ni}$ & 1.328043 & -0.315392 & 0.007794 \\
\hline $\mathrm{Ni}$ & -0.939246 & -0.991770 & 0.000321 \\
\hline $\mathrm{Ni}$ & -0.391373 & 1.309927 & -0.000470 \\
\hline $\mathrm{O}$ & -1.916220 & 0.456836 & -0.004997 \\
\hline $\mathrm{O}$ & 1.351628 & 1.431724 & 0.005717 \\
\hline $\mathrm{O}$ & 0.561963 & -1.885771 & 0.006944 \\
\hline
\end{tabular}

$\begin{array}{lrrr}\mathbf{( N i O})_{4}(\mathbf{2 S}+\mathbf{1}=\mathbf{9}) & & \\ \mathrm{Ni} & 0.070829 & 1.828745 & 0.000000 \\ \mathrm{Ni} & 1.828745 & -0.070829 & 0.000000 \\ \mathrm{Ni} & -0.070829 & -1.828745 & 0.000000 \\ \mathrm{Ni} & -1.828745 & 0.070829 & 0.000000 \\ \mathrm{O} & -1.692371 & 1.828745 & 0.000000 \\ \mathrm{O} & 1.828745 & 1.692371 & 0.000000 \\ \mathrm{O} & 1.692371 & -1.828745 & 0.000000 \\ \mathrm{O} & -1.828745 & -1.692371 & 0.000000\end{array}$

$(\mathrm{NiO})_{5}(\mathbf{2 S}+\mathbf{1}=\mathbf{1})$

$\begin{array}{lrrr}\mathrm{Ni} & -1.689008 & -1.316697 & 0.000000 \\ \mathrm{Ni} & 0.000000 & 2.141276 & 0.000000 \\ \mathrm{O} & -0.226516 & -2.169247 & 0.000000 \\ \mathrm{O} & 3.100084 & -1.513929 & 0.000000 \\ \mathrm{O} & -3.117102 & -0.380766 & 0.000000 \\ \mathrm{O} & -1.616188 & 2.691967 & 0.000000 \\ \mathrm{O} & 1.571773 & 1.512588 & 0.000000 \\ \mathrm{Ni} & 2.509022 & 0.103910 & 0.000000 \\ \mathrm{Ni} & 1.460650 & -2.042097 & 0.000000 \\ \mathrm{Ni} & -2.198393 & 1.073433 & 0.000000\end{array}$

$(\mathrm{Ni})_{2}(2 \mathrm{~S}+1=3)$ 


$\begin{array}{llrr}\mathrm{Ni} & 0.000000 & 0.000000 & 1.069862 \\ \mathrm{Ni} & 0.000000 & 0.000000 & -1.069862\end{array}$

$\begin{array}{lrcc}\left(\mathbf{N i}_{\mathbf{2}} \mathbf{O}\right) & (\mathbf{2 S}+\mathbf{1}=\mathbf{3}) & & \\ \mathrm{Ni} & 0.000000 & 1.163547 & -0.159996 \\ \mathrm{Ni} & -0.000000 & -1.163547 & -0.159996 \\ \mathrm{O} & 0.000000 & -0.000000 & 1.119974\end{array}$

(Ni) $3(2 \mathrm{~S}+1=3)$

$\begin{array}{lrrr}\mathrm{Ni} & 0.000000 & 1.286404 & 0.000000 \\ \mathrm{Ni} & 1.119340 & -0.633987 & 0.000000 \\ \mathrm{Ni} & -1.119340 & -0.652416 & 0.000000\end{array}$

$\begin{array}{lrcc}\left(\mathbf{N i}_{\mathbf{3}} \mathbf{O}\right) & (\mathbf{2} \mathbf{S}+\mathbf{1}=\mathbf{5}) & & \\ \mathrm{Ni} & 0.494537 & -1.142170 & -0.093452 \\ \mathrm{Ni} & 0.494392 & 1.142205 & -0.093455 \\ \mathrm{Ni} & -1.495323 & -0.000064 & 0.073094 \\ \mathrm{O} & 1.772377 & 0.000103 & 0.398343\end{array}$

$\begin{array}{lrcc}\left(\mathbf{N i}_{3} \mathbf{O}_{2}\right) & (\mathbf{2 S}+\mathbf{1}=\mathbf{3}) & & \\ \mathrm{Ni} & 1.216779 & -0.854176 & 0.000000 \\ \mathrm{Ni} & -1.216805 & -0.854714 & -0.000000 \\ \mathrm{O} & 1.679226 & 0.797553 & 0.000000 \\ \mathrm{O} & -1.679134 & 0.797039 & -0.000000 \\ \mathrm{Ni} & 0.000000 & 1.253291 & 0.000000\end{array}$

$\left(\mathrm{Ni}_{4} \mathrm{O}_{2}\right)(2 \mathrm{~S}+\mathbf{1}=3)$

$\begin{array}{rrrr}\mathrm{Ni} & -0.827327 & -0.748011 & -1.068498 \\ \mathrm{Ni} & -0.915978 & 0.075278 & 1.243093 \\ \mathrm{Ni} & 1.112711 & -0.945770 & 0.346563 \\ \mathrm{Ni} & 0.450366 & 1.256149 & -0.362709 \\ \mathrm{O} & -1.374122 & 0.818017 & -0.362586 \\ \mathrm{O} & 2.004921 & 0.450223 & -0.191987\end{array}$

$\begin{array}{lrrr}\left(\mathbf{N i}_{4} \mathbf{O}_{3}\right) & (\mathbf{2 S}+\mathbf{1}=\mathbf{3}) & & \\ \mathrm{Ni} & -0.999957 & 0.249472 & 1.158076 \\ \mathrm{Ni} & -0.985685 & -0.444071 & -1.112557 \\ \mathrm{Ni} & 0.750493 & 1.218705 & -0.222483 \\ \mathrm{Ni} & 1.099198 & -1.058078 & 0.163461 \\ \mathrm{O} & -0.670724 & -1.462590 & 0.448069 \\ \mathrm{O} & 2.231266 & 0.284988 & 0.010914 \\ \mathrm{O} & -1.084718 & 1.296500 & -0.411722\end{array}$

$\left(\mathrm{Ni}_{5} \mathrm{O}_{3}\right)(2 \mathrm{~S}+1=5)$

\begin{tabular}{|c|c|}
\hline $\mathrm{Ni}$ & -0.305533 \\
\hline $\mathrm{Ni}$ & -0.30755 \\
\hline
\end{tabular}




$\begin{array}{rrrc}\mathrm{Ni} & 0.428512 & 0.017715 & 1.400640 \\ \mathrm{Ni} & -2.038145 & 0.007998 & 0.473687 \\ \mathrm{O} & -1.609560 & -0.015224 & -1.320454 \\ \mathrm{Ni} & 2.014405 & -0.006530 & -0.398175 \\ \mathrm{O} & 1.187284 & 1.459059 & 0.375388 \\ \mathrm{O} & 1.184819 & -1.450562 & 0.412472\end{array}$

$\begin{array}{lrrr}\left.\mathbf{( N i} \mathbf{O}_{4}\right) & (\mathbf{2 S}+\mathbf{1}=\mathbf{5}) & & \\ \mathrm{Ni} & 0.006762 & 0.017516 & -1.339334 \\ \mathrm{Ni} & -1.373192 & 1.261698 & 0.215626 \\ \mathrm{Ni} & 1.417188 & 1.206952 & 0.230885 \\ \mathrm{Ni} & 1.211528 & -1.257850 & 0.325735 \\ \mathrm{Ni} & -1.266030 & -1.209339 & 0.311517 \\ \mathrm{O} & 0.039204 & 1.816149 & -0.833176 \\ \mathrm{O} & 2.207819 & -0.065789 & 1.120634 \\ \mathrm{O} & -2.223210 & 0.021086 & 1.095954 \\ \mathrm{O} & -0.031058 & -1.791036 & -0.909245\end{array}$

$\begin{array}{lrrr}\left(\mathbf{N i}_{\mathbf{6}} \mathbf{O}_{4}\right)(\mathbf{2} \mathbf{S}+\mathbf{1}=\mathbf{3}) & & \\ \mathrm{Ni} & -0.005864 & 1.268372 & -1.201304 \\ \mathrm{Ni} & -0.003204 & 1.217069 & 1.251257 \\ \mathrm{Ni} & 0.012111 & -1.267296 & 1.202325 \\ \mathrm{Ni} & 0.009301 & -1.216475 & -1.252241 \\ \mathrm{Ni} & -1.815499 & -0.011485 & 0.001597 \\ \mathrm{Ni} & 1.782067 & 0.009701 & -0.001641 \\ \mathrm{O} & -1.236479 & -0.042329 & 1.733593 \\ \mathrm{O} & -1.239924 & 0.029036 & -1.731309 \\ \mathrm{O} & 1.284766 & -1.767349 & -0.037217 \\ \mathrm{O} & 1.265443 & 1.781041 & 0.034956\end{array}$

$\begin{array}{lrrr}\left(\mathbf{N i}_{\mathbf{6}} \mathbf{O}_{\mathbf{5}}\right) & (\mathbf{2 S}+\mathbf{1}=\mathbf{5}) & & \\ \mathrm{Ni} & 1.75401900 & 0.61705900 & -0.81145800 \\ \mathrm{Ni} & -0.55793700 & 0.41788500 & -1.52753800 \\ \mathrm{O} & 0.91721500 & 0.96393500 & -2.29230300 \\ \mathrm{Ni} & -1.76618600 & 0.80089400 & 0.57056800 \\ \mathrm{Ni} & 0.51343300 & 0.96477700 & 1.30351600 \\ \mathrm{Ni} & 1.17083400 & -1.32890700 & 0.59707400 \\ \mathrm{O} & 2.14221800 & 0.19121000 & 0.94212200 \\ \mathrm{O} & 0.06514300 & -2.67278900 & 0.45206600 \\ \mathrm{O} & -0.94476600 & 1.80317600 & 1.76500800 \\ \mathrm{Ni} & -1.11196900 & -1.49233200 & -0.11936000 \\ \mathrm{O} & -2.18748900 & -0.21334800 & -0.91170300\end{array}$

$\left(\mathrm{Ni}_{7} \mathrm{O}_{5}\right)(\mathbf{2 S}+\mathbf{1}=\mathbf{1 1})$

$\begin{array}{llll}\mathrm{Ni} & 2.18367800 & -0.05438700 & -0.00117000\end{array}$

$\mathrm{Ni} \quad \begin{array}{llll}0.43376100 & 1.23390900 & 1.18050400\end{array}$ 


$\begin{array}{lrrr}\mathrm{Ni} & -1.75498000 & 1.23160800 & 0.00045900 \\ \mathrm{Ni} & 0.36380700 & -1.24032500 & -1.17963200 \\ \mathrm{Ni} & 0.42552800 & 1.21082600 & -1.19704200 \\ \mathrm{Ni} & 0.35790400 & -1.21789700 & 1.19642800 \\ \mathrm{Ni} & -1.83170400 & -1.16950200 & 0.00351500 \\ \mathrm{O} & -0.48413200 & -2.41086200 & 0.01690000 \\ \mathrm{O} & -3.08002100 & 0.07363700 & -0.00994800 \\ \mathrm{O} & 1.65609500 & -0.02571100 & 1.81512100 \\ \mathrm{O} & 1.65505600 & -0.05168200 & -1.81642600 \\ \mathrm{O} & -0.36997600 & 2.43480500 & -0.01636100\end{array}$

$\begin{array}{lrrr}\left.\mathbf{( N i} \mathbf{O}_{6}\right) & (\mathbf{2 S}+\mathbf{1}=\mathbf{9}) & & \\ \mathrm{Ni} & 1.53661500 & -1.44236500 & -0.06564000 \\ \mathrm{Ni} & 1.53483400 & 0.66487600 & 1.28303400 \\ \mathrm{Ni} & -0.45699400 & 1.54340600 & 0.06995100 \\ \mathrm{Ni} & -0.45654200 & -0.71176700 & -1.37066500 \\ \mathrm{Ni} & 1.53736100 & 0.77856800 & -1.21662300 \\ \mathrm{Ni} & -0.45677600 & -0.83311900 & 1.30126200 \\ \mathrm{Ni} & -2.50261500 & 0.00026900 & -0.00089500 \\ \mathrm{O} & -2.18716200 & -0.80174900 & -1.54739200 \\ \mathrm{O} & -2.18740100 & 1.74065100 & 0.07912100 \\ \mathrm{O} & 1.32882500 & -1.11635800 & 1.74456000 \\ \mathrm{O} & 1.32896800 & -0.95244800 & -1.83895400 \\ \mathrm{O} & 1.32864800 & 2.06872100 & 0.09403900 \\ \mathrm{O} & -2.18746700 & -0.93835800 & 1.46714400\end{array}$

\section{SI References}

1. C. J. Dibble, S. T. Akin, S. Ard, C. P. Fowler, M. A. Duncan, Photodissociation of cobalt and nickel oxide cluster cations. J. Phys. Chem. A 116, 5398-5404 (2012).

2. G. C. Nieman, et al., Multiphoton ionization and fragmentation of transition-metal cluster oxides. High Temp. Sci. 22, 115 (1986).

3. M. J. Frisch, et al., Gaussian16 (Revision C.01), Gaussian Inc. Wallingford CT (2016).

4. J. P. Perdew, Y. Wang, Accurate and simple analytic representation ofthe electron-gas correlation energy. Phys. Rev. B 45, 13244-13249 (1992). 